\title{
Wishful Thinking and the Unconscious: A Reply to Gouws
}

\author{
Elisa Galgut \\ Department of Philosophy \\ University of Cape Town \\ Private Bag \\ Rondebosch 7700 \\ South Africa \\ E-mail: egalgut@humanities.uct.ac.za
}

\begin{abstract}
This paper argues against the view that the Freudian unconscious can be understood as an extension of ordinary belief-desire psychology. The paper argues that Freud's picture of the mind challenges the paradigm of folk psychology, as it is understood by much contemporary philosophy of psychology and cognitive science. The dynamic unconscious postulated by psychoanalysis operates according to rules and principles that are distinct in kind from those rules that organise rational and conscious thought. Psychoanalysis offers us a radical reconception of our ordinary way of thinking about our own minds.
\end{abstract}

In a recent paper in this journal, Andries Gouws sketches a "reconstruction of the Freudian unconscious, and an argument for its existence." He provides a defense of the Freudian notion of the unconscious in the hopes of bolstering the claims of psychoanalysis against Cartesian-type scepticism of its existence. He writes: "The strategy followed attempts to side-step the extended debates about the validity of Freud's methods and conclusions, by basing itself on the desire/belief schema for understanding and explaining human behaviour - a schema neither folk psychology nor scientific psychology can do without" (Gouws 2003: 361) Gouws outlines two different kinds of mental processing: one governed by rational thought, and the other by wishful thinking. His argument is that wishful thinking requires an unconscious because "it is inimical to a clear, complete and unambiguous acknowledgement of its own status." What distinguishes wishful thinking from rational thought, in his view, is that the wishful thinker distorts reality in the light of her desires. Wishes, unlike rational thoughts like beliefs, do not modify themselves in response to the obstacles reality might present; rather, reality is either ignored or distorted in the service of the wish. He points out (rightly) that wishful thinking must disguise its true nature in order to be effective; he then concludes that this is evidence for the existence of the Freudian unconscious. "My ultimate aim," he writes, "is to show how wishful thinking gone rampant can lead to something like an unconscious." For Gouws, wishful thinking and rational thought "form two ends of a continuum, not a dichotomy"; he states that "Our view dispenses with any line pretending to divide the unconscious from the preconscious (Freud flounders every time he presents them as a dichotomy, rather than a continuum)" (Gouws 2003: 362). Thus wishful thinking must be a species of belief-desire psychology, the schema of folk psychology. Wishful thinking (and other irrational phenomena 
such as self deception) can be explained, on this model, by the various failures to accommodate the demands of reality that frustrate or otherwise hamper the fulfilment of desires. Wishful thinking ignores the constraints within which "realistic thinking" operates.

I do not wish to discuss the details of Gouws's project, even though I am uncertain whether he has provided the defence he hoped for of the Freudian unconscious. It seems to me that it might be possible to deal with various cases of wish fulfilment and self deception by routes other than that of positing an unconscious. ${ }^{1}$ What worries me is the deeper issue concerning the nature of the mental - namely the claim that wishful thinking and rational belief lie on either end of a single continuum. If one accepts this claim, then the very nature of the Freudian unconscious ${ }^{2}$ is at stake; if wishes are very much like desires, then the grammar (if you will) of the unconscious will be similar to the grammar of rational beliefs and desires. Or, to put it another way, primary mental processing (which governs the unconscious) will not be radically different from secondary mental processing (which governs the conscious / preconscious). ${ }^{3}$ Gouws is not alone in his portrayal of the unconscious - the debate concerning the nature of psychoanalytic entities has a long history; the claim is often made that Freud simply extended our ordinary folk psychological concepts and explanations of human behaviour. Part of the temptation to see psychoanalysis as an extension of ordinary psychological thinking lies in the desire to see what Freud and his followers were doing as giving us a deeper understanding of what we'd already - on some level or another known all along. What we gain from psychoanalysis in return for learning that we are less rational than we had thought is the promise that the irrational, ultimately, is explicable in terms of - or reducible to - the rational. The difference between the rational and the irrational is that irrational thoughts and behaviours are caused by beliefs and desires that are unconscious, and once these are made conscious, the thought or action can be seen to be perfectly reasonable by the lights of the person who has them. Those who argue for the similarity between ordinary and psychoanalytic explanations of the mind hope to show that the only difference between an ordinary belief and an unconscious one lies precisely (and simply) in the fact that the latter is unconscious. It is this appeal to unconscious beliefs and desires that provides the bridge between psychoanalytic and ordinary folk psychological explanations: by widening the scope of intentional explanation, psychoanalysis shows us that the irrational is different in degree, but not different in kind, from garden variety belief-desire psychology. And yet, as Wittgenstein pointed out, the term "unconscious", when used as an adjective, changes the noun it modifies. Just as a straw man is not a kind of man at all, so an unconscious desire is not really like an ordinary desire, nor an unconscious belief like a ordinary belief. The Freudian unconscious splits the mind in more radical ways than Gouws's paper - and the tradition he is defending - allows. This characterisation of the unconscious and of the differences that exist in mental functioning is, to my mind, one of the major contributions of psychoanalysis to the way we think about ourselves, and Freud's claims flourish, rather than flounder, in its wake.

1 See, for instance, the writings of Alfred Mele, Donald Davidson and Robert Audi on self deception.

2 From here on, I'll use the term "unconscious" to refer to the Freudian notion of the dynamic unconscious, unless otherwise stated.

3 I am aware that the language used here is derived from Freud's topographical schema, which is a crude mental model that Freud himself refined. I use the terms to refer to broad types of mental functioning, leaving untouched the more complex issues. 
Defending this claim fully requires much more than a short paper, but I'd like to outline a few points in its defence. Perhaps a good way to do this is to examine the processes Gouws himself discusses as characterising the nature of the primary processes, and show how these features point to a different kind of mental processing that is radically different from that exhibited by the secondary processes. Gouws mentions two ways in which primary processes fail to be constrained by reality; the primary processes fail to look at things "in a larger context", and they disregard "the constraints placed on the correct use of language." Failure to look at things in a larger context means "matching a desire with its satisfaction, without considering whether it is compatible with a larger field of facts and desires, over a longer period. A maximum fragmentation ... gives the greatest release from the constraints imposed by other desires, the facts and the time frame. Each desire then seeks satisfaction separately, without considering the consequences for other desires" (Gouws 2003: 368). Framing the discussion in this way, it becomes apparent that, for Gouws, wishes are a species of desire, and wishful thinking is allied to ordinary thinking: when engaged in wishful thinking, one fails to look at things in a larger context, or one fails to consider such and such. The concepts are cognitive. But this flies in the face of Freud's discoveries; it is not the case that the neurotic or the hysteric simply overlooks certain facts, or fails to consider the consequences of his or her desires. For the most part, the neurotic is unable to integrate many of the "facts" presented by reality into his cognitive framework; the hysteric is not only unaware of many of her desires, but would also be incapable of neatly distinguishing one desire from another. Perhaps an example would make this clearer. In his Introductory Lectures, Freud discusses the case of a patient of his, who suffered from obsessional neurosis. She performed the following activity several times a day: "She ran from her room into another neighbouring one, took up a particular position there beside a table that stood in the middle, rang the bell for her housemaid, sent her on some indifferent errand ... and then ran back into her own room." The reason for this compulsive activity could be traced to an incident on her wedding night; her husband, who was much older than she, was impotent. Embarrassed that this would be discovered by the housemaid in the morning, he poured red ink on the bed sheet, "but not in the exact place where a stain would have been appropriate ... I could not understand at first what this recollection had to do with the obsessional action in question ... My patient then led me up to the table in the second room and showed me a big stain on the tablecloth. She further explained that she took up her position in relation to the table in such a way that the maid who had been sent for could not fail to see the stain. There could no longer be any doubt of the intimate connection between the scene on her wedding-night and her present obsessional action, though all kinds of other things remain to be learnt" (Freud 1981: 301). From this example, one sees that the symptom is not an action in the ordinary sense of the term, nor is it a straightforward satisfaction of a desire that can be clearly articulated. Symptoms are very often compromises between mutually inconsistent desires, and it is mistaken to think that a neurotic symptom satisfies a desire in the way that, say, eating satisfies the desire to avoid hunger. This can be seen further in the way that symptoms generally fail to satisfy the wishes that they "set out" to satisfy: the wife's pointing out a stain on the tablecloth was a very poor defence of her husband's reputation as a virile lover - especially since the stain that was made was an ink stain, and was not, in actual fact, proof of her lost virginity. So it is very difficult to think of a symptom as satisfy-

4 I use the inverted commas to show that this "setting out" to satisfy a wish is not intentional. 
ing a desire in any ordinary sense - it is only when the convoluted unconscious thoughts are untangled that we begin to make any sense of the meaning of the symptom. And even then, this meaning is understood very often only partially, by means of a complex theory, and in no way amounts to the kind of ordinary "making sense" that we employ in folk psychological explanations.

Another important reason for this lies in the very nature of wish fulfilment; as Gouws rightly points out, secondary processes deal with the satisfaction of desires in reality. My desire for chocolate impels ${ }^{5}$ me to go to the local store to buy an Aero; should the store be closed, or should Aeros be sold out, I'll try other avenues (visit a fellow chocolate-loving friend, or buy a Kit Kat instead). The point about genuine desires is that they are sensitive to the evidence external reality brings to them ("there is no chocolate of the kind you want here"); we are also aware of whether our desires are being fulfilled - offer me a carob bar instead of a chocolate bar, and I'll refuse. I might, of course, temper or alter my desires over time - realising that I need to lose weight, I might restrict my chocolate intake, or, if warned of the dangers of eating too much chocolate, I might indeed succumb tentatively to your offer of a carob bar. Desires are structured so that the aim of the desire is separate from the object that satisfies it; the action of the agent fills the gap, either acquiring the object so as to satisfy the desire, or making alternative arrangements if the desire cannot be fulfilled. The gap provides the soil in which the reality principle begins to take root; the gap is indicative of the existence of a reality external to the self and its bundle of desires. Wishes, however, are quite different; without therapeutic intervention, they are neither influenced by reality, nor are they altered easily over time. A wish does not distinguish between what it wants and the object that will satisfy these wants; aim and object are collapsed. To put it another way, a wish does not distinguish between the conditions of its satisfaction, and its actually being satisfied. ${ }^{6}$ Let's take the paradigmatic case of wish fulfilment: a baby's hallucination of the breast. In imagining the breast, the infant is fulfilling its wish to be satiated. The hallucination is simultaneously the expression of the wish to be fed, and its fulfilment: hallucinating is all that the infant need (can) do in order to satisfy its wish to be satiated. Of course, because wishes are not horses (or breasts), the activity of hallucinating does not, ultimately, bring any real satisfaction, and is eventually relinquished in favour of activities more likely to end hunger. That's just the point about wishes - they are governed by primary processes, and are insensitive to reality. And this is precisely why they differ from desires. Returning to the case of the impotent husband, we can see that the wife's wish to preserve her husband's reputation is more like an hallucination than it is like a desire: the activity of pointing out the stain on the table cloth is an enactment of her wish in the same way that the baby's hallucination of the breast is an enactment of its desire to be satisfied. In either case, it would be inappropriate to use the discourse of intentional action, of activities performed for a reason. Even though the wife doesn't actually hallucinate, her wish distorts her perception of reality - table cloths with coffee stains on them are perceived as bed sheets with blood stains on them; or, to put it another way, the evidence that reality might bring ("this is a table cloth with a coffee stain") is ignored in the light of the wish. In the symptom, internal reality trumps external reality. Of course, this occurs in degrees - the neurotic has a greater hold on reality than the psychotic, for whom inner

5 Or compels, depending on the level of my desire and the state of my chocolate stash at home!

6 For further discussion on this point, see the works of Sebastian Gardner and James Hopkins. 
reality and primary processing all but replace external reality and secondary processing.

This brings me to Gouws's second point regarding the differences between primary and secondary processing - "Disregarding the constraints placed on the correct use of language." "In wishful thinking," he writes, "such confusions [errors in language] are actively courted, the ambiguities of language exploited to the hilt, and verbal solutions to problems equated to actual solutions." These features of the unconscious, of wishful thinking can be seen, Gouws writes, "as extensions of everyday 'indirect' or 'figurative' uses of language ... This is made easier by the very nature of language: the rules imposed by language are often unclear"(Gouws 2003: 369). Once again, Gouws hopes to show how the rules governing primary processing are not radically different from those governing secondary processing. But once again I would like to offer an alternative suggestion, which is that the unconscious does not function like a rule-governed language at all. In the unconscious, semantic and syntactic rules break down. For instance, there is, as Freud pointed out, no negation: in the unconscious there is no way to represent a negative proposition. Words and things have the same ontological status, as it were, which accounts for the power wishful thinking seems to have to itself: words have the same causal efficacy as do objects in the real world. This fantasy about the power of language underlies many religious beliefs concerning magic, for instance. It also explains the power of other kinds of "special words", like curses, charms, and, poetry. It's not simply the case that the ambiguities of language are "exploited to the hilt", for such exploitation implies that the rules of language are known, but are bent to the will of the wish. But in the unconscious, the rules of language cease to operate; semantic and syntactic rules are replaced by association, an association in which the distance between the things associated collapses to zero. It's not simply that A stands for $\mathrm{B}$ - by standing for $\mathrm{B}$, A becomes $\mathrm{B} .^{7}$ It is this feature of the unconscious that allows for condensation and displacement: in condensation, parts of an object "stand in" for the whole object, and objects that are perceived as being similar in certain respects then are "collapsed" into one. In displacement, common elements are transferred from one object onto another. Other operations of the unconscious display similar characteristics, and illustrate the fundamental differences between primary and secondary processing.

Again, it is these differences that are elided in the discussion of the nature of wish fulfilment. This is not a trivial issue; the very picture of the mind is at stake. By placing wish fulfilment and the reality principle at opposite ends of the same spectrum, one is remaining firmly fixed within the Cartesian paradigm - even though it's not the case that everything mental is conscious, everything mental is certainly easily capable of becoming conscious, which is why I am doubtful that the arguments presented from this perspective strongly support the existence of an unconscious. For one of the central tenets of psychoanalysis is that there are mental items that are not easily accessible to consciousness; indeed, there may very well be aspects of the mind that will never become conscious, even with decades of analysis. And the reason isn't resistance

7 In The Unconscious as Infinite Sets, Matte Blanco expresses the characteristics of primary processing in terms of a "principle of symmetry". He argues that differences between items in the unconscious are erased by being collapsed into relations of identity. 
alone, if that is interpreted in the sense of the conscious mind ${ }^{8}$ not wishing to acknowledge certain unpleasant, buried fantasies. The reason, as I've been stressing, is the fundamental differences between conscious and unconscious mental processing.

In order to highlight these differences further, I'll turn to Gouws's analysis of three features of mental life that exhibit primary process functioning. These are dreams, speech in the analytic situation, and psychosis. Gouws states that "All three of these phenomena which psychoanalysis takes to be paradigmatic for the unconscious can thus be seen as resulting from the easing of the constraints usually governing our dealings with reality in the rational, realistic mode" (Gouws 2003: 367). Well - yes and no. I am certainly in agreement that these three cases are paradigm examples of primary process thinking, but, firstly, they are not all on a par, and secondly, primary process thinking does not result simply as a result of easing the constraints that govern our dealings with reality. The second point first: let's look at another example of mental life that holds sway when the "rational, realistic mode" loosens its hold on us daydreaming. In my daydreams, I am a winner at Wimbledon, holding aloft the trophy and shaking the hand of the Duchess of Windsor. My daydream may be as elaborate and as detailed as I wish, and may be as unrealistic as I wish. In another daydream, I fly through the stars to Twin Earth, and have tea with my Twin Earth self, Queen Elizabeth I and Sherlock Holmes. These daydreams are certainly possible only when I wilfully ignore the constraints of reality - as soon as I start to perform all the necessary computations in order to ascertain when would be the best time to leave for my trip, and what I should pack, I'll realise the futility of the enterprise. Similarly (and sadly) my dreams of winning Wimbledon are unrealistic, even though such daydreams seem closer to this world than to some other possible one. But daydreams, although they can function only when reality is bracketed, do not exhibit the features of primary process thinking; when I daydream, I normally suspend my beliefs about the real world, but this is a different sort of enterprise from the avoidance of reality that marks the features of neurotic symptoms and psychoses. When daydreaming, I am able to recognise reality when it shows its face - for one thing, the process of daydreaming is given up fairly easily - the shout from the teacher to pay attention, the thought that I must buy groceries before the shops close, and so on. I thus want to argue that not all kinds of wishful thinking are equal to one another - there are different kinds of wishful thinking, and some are more impervious to the demands of reality than others. Wherein lies the difference? The answer is: in how far seeped in unconscious material the wishful thoughts are. Daydreaming lies pretty close to the surface of our mental life, whereas neurotic symptoms, dreams and psychosis, lying "further down", as it were, are more "saturated" "with primary process functioning. When Gouws discusses dreams, speech in the analytic situation, and psychosis, he seems to treat them as if they are instances of the same mental species; saying that they all feature elements of the failure of "feedback mechanisms" is an inadequate way of illustrating the fundamental differences between, say, being in a psychotic state and being in the analytic situation. In-

8 This talk of the "conscious mind" "hiding things" from the "unconscious mind" is problematic, since it tends to portray the mind as divided into homuncular parts. This is a picture that I want very strongly to resist - we should think of the terms "conscious" and "unconscious" as functional, and not spatial, descriptions. This tendency to think of the mind as situated is a remnant of a Cartesian picture of the mind as a separate kind of substance, even though Descartes himself was at pains to point out that the mind is not spatial.

9 Finding the appropriate metaphor to talk about the unconscious is difficult! The tendency to talk about the mind as spatial is difficult to relinquish. 
deed, when talking about psychosis, he writes that "The realistic fulfilment of desires is impeded, frustration mounts, wishful thinking holds sway, and the stage is set for a vicious circle" (Gouws 2003: 367). But this seems to be an inadequate account of what happens in psychosis; for one thing, it's not clear that the psychotic experiences frustration - I suppose it depends on the nature and the extent of the psychosis. In some psychotic episodes, if the person is sufficiently far removed from reality, the mind may be so in the grip of the primary process that there is no room for frustration. And again - the kind of "wishful thinking" that holds sway for the psychotic is of a different degree entirely from the kind of wishful thinking I engage in when I dream about winning Wimbledon or travelling to Twin Earth. In psychosis, it's hard to know whether many psychotic acts can be labelled "thinking" at all, where "thoughts" in this case are understood as cognitive ${ }^{10}-$ i.e. governed by secondary processes. We certainly would not wish to place the experience of the psychotic and that of the ordinary analysand in the same category - and yet the claim that secondary and primary process thinking are not that dissimilar threatens to do just that. With regard to the neurotic, Freud wrote famously that the aim of analysis is to give the person more control over her life, so that the forces of the unconscious no longer dominate - "Where Id is, there Ego shall be." This, of course, presupposes that in the neurotic, there is a difference between Id and Ego, between primary and secondary process thinking, and the latter is, by and large, the dominant form of discourse. In psychosis, there is no hope of extending the domain of the Ego - in the grip of the psychosis, the Ego resembles the shell of a burned-out shelter rather than any kind of habitable abode.

By now, the central point of my paper should be clear: that it is a mistake to draw the distinction between primary and secondary processes as a mere difference in degree between items that belong to the same mental type. This kind of analysis of the mind fails to take seriously the radical picture that psychoanalysis presents to us. I am certainly in favour of accommodating psychoanalysis in contemporary cognitive accounts of the mental, but we must be wary not to confuse the kinds of "unconscious" processes that cognitive psychologists talk about with the dynamic unconscious that is Freud's legacy to us. For Freud, the unconscious was not simply that which is unknown, but that which is unknowable. Making the unconscious conscious requires changing the structures that govern mental life - no trivial exercise. If we really wish to place psychoanalysis outside the Cartesian landscape, we need to take full account of the nature of those mental states - wishes and phantasies - that cannot be fully articulated in the language of cognitive psychology. The unconscious, contrary to Lacan's dictum, is not structured like a language, at least not if we understand "language" as the subject matter of linguistics. Certainly the unconscious has a method of its own; certainly there are principles that govern the primary processes - these methods and principles form the subject matter of psychoanalysis. That is why clarifying the domain of the unconscious - demarcating its borders, giving conditions of citizenship - is important. Like the past, the unconscious is another country, and, like the past, it is not a habitable region; although it's true that humans cannot bear too much reality, we cannot bear too much phantasy either.

10 And one of the central contributions of psychoanalysis has been to show us that "thoughts" are not only cognitive. 


\section{Bibliography}

Freud, S. 1981 "The Sense of Symptoms" Lecture 17 in Introductory Lectures on Psychoanalysis (The Pelican Freud Library Volume 1) Middlesex: Penguin Books, 296-312

Freud, S. 1985 “On Negation” On Metapsychology: The Theory of Psychoanalysis (The Pelican Freud Library Volume 11). Harmondsworth, Middlesex: Penguin Books, 435-442.

Gouws, A. 2003 "Wishful thinking and the unconscious" South African Journal of Philosophy 22(4) 361-377.

Matte Blanco, I. 1975 The Unconscious as Infinite Sets. London: Duckworth. 
Copyright of South African Journal of Philosophy is the property of Philosophical Society of Southern Africa (PSSA) and its content may not be copied or emailed to multiple sites or posted to a listserv without the copyright holder's express written permission. However, users may print, download, or email articles for individual use. 